\title{
Case Report \\ Primary Non-Hodgkin's Lymphoma of the Scalp and Cranial Vault
}

\author{
Jovita Martin, ${ }^{1}$ Anita Ramesh, ${ }^{1}$ Muhamed Kamaludeen, ${ }^{1}$ Udhaya, ${ }^{1}$ \\ K. Ganesh, ${ }^{2}$ and Jude J. Martin ${ }^{3}$ \\ ${ }^{1}$ Department of Oncology, Sri Ramachandra Medical College, Chennai 600116, India \\ ${ }^{2}$ Department of Neurosurgery, Sri Ramachandra Medical College, Chennai 600116, India \\ ${ }^{3}$ Trinity \& Co., Saidapet, Chennai 600015, India \\ Correspondence should be addressed to Jovita Martin, dr.jovithamartin@yahoo.com
}

Received 18 November 2011; Accepted 20 December 2011

Academic Editor: N. S. Litofsky

Copyright () 2012 Jovita Martin et al. This is an open access article distributed under the Creative Commons Attribution License, which permits unrestricted use, distribution, and reproduction in any medium, provided the original work is properly cited.

Primary Non-Hodgkin's Lymphoma of the cranial scalp and skull vault is a rare disease. We are describing a case of the same in
a 50 -year-old man. He was presented with a diffuse swelling in the left side scalp since 4 months of duration and progressively
enlarging in size. On local Examination of the scalp, there was a diffuse swelling in the left parietal and occipital region of scalp.
Imaging showed diffuse infiltration of the skull vault with extracranial soft tissue masses. Further investigations with CT scan
chest, abdomen, and pelvis did not reveal any other evidence of systemic lymphoma. Biopsy of one of the scalp masses showed a
small to intermediate cell B-cell lymphoma. Other nine previously reported cases of primary skull vault lymphoma were reviewed.

\section{Introduction}

Primary Non-Hodgkin's Lymphoma of the skull with extraand intracranial extension without systemic or skeletal manifestation in a nonimmunocompromised patient is extremely rare. Till date, only nine such cases have been reported in the literature and in none was the lesion located in the midline [1].

\section{Case Report}

A 50 years male, with 4 months duration of a diffuse swelling in the left side scalp. On local Examination Diffuse swelling in the left parietal and occipital scalp more than $10 \times 10 \mathrm{~cm}$, irregular surface, skin over the swelling normal, patchy loss of hair, no tenderness, no transparency or translucency, no pulsation (Figure 1). On general examination there were no other lymph nodes or organomegaly. At that point the clinical diagnosis was soft tissue sarcoma. On blood investigations all the blood parameters were normal, hepatitis $\mathrm{B}$ antigen was positive. Bone marrow aspiration study was normal.
Computed tomographic examination showed Swelling (soft tissue opacity) in the left Parietal region, the surrounding parietal and occipital bones shows bony erosions with cortical thickening and periosteal reaction withmotheaten pattern of destruction. There is associated component of subdural collection (Figures 2 and 4). There was no concurrent nodal or intracranial (extradural/meningeal) involvement or invasion of the orbit. Further staging workup was completed. The CT of the chest and abdomen/pelvis did not reveal any other sites of disease. Histologic examinations revealed diffuse primary cutaneous B-cell lymphoma of the scalp Stage I EA (according to the Revised European-American Lymphoma (REAL) classification). The immunohistochemistry showed CD 20, CD 45 positive (Figure 3).

The patient was treated with surgery with partial removal of the scalp lesion followed by 6 cycles of chemotherapy with injection cyclophosphamide, doxorubicin, vincristine, and tab. predonisolone. (CHOP regimen) and showed good response with regression of the cutaneous lesions. Local adjuvant External beam Radiotherapy of 36 Gy @ 2 Gy per fraction in 18 fraction for a period of 3 weeks, is planned to be given to the left scalp region was given with $9 \mathrm{MeV}$ electrons. 


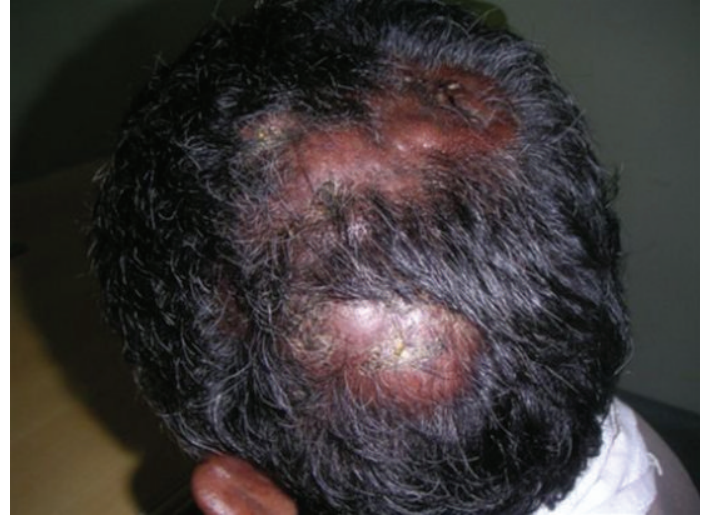

(a)

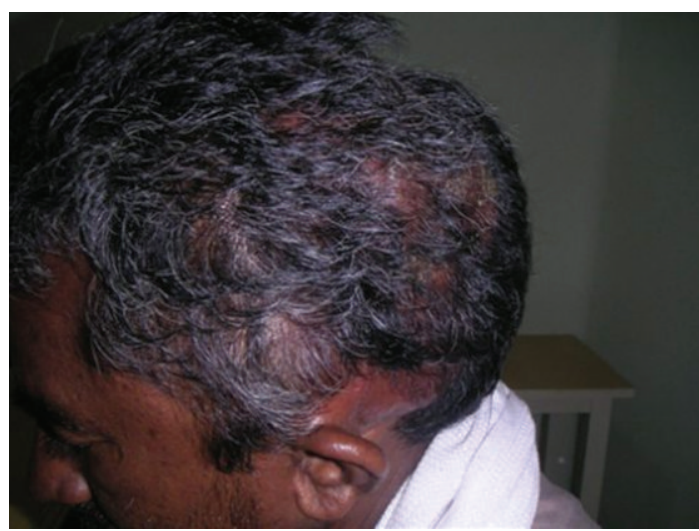

(b)

FIgURE 1: (a) Scalp mass in the left temporoparietal region. (b) Scalp mass in the left temporoparietal region.

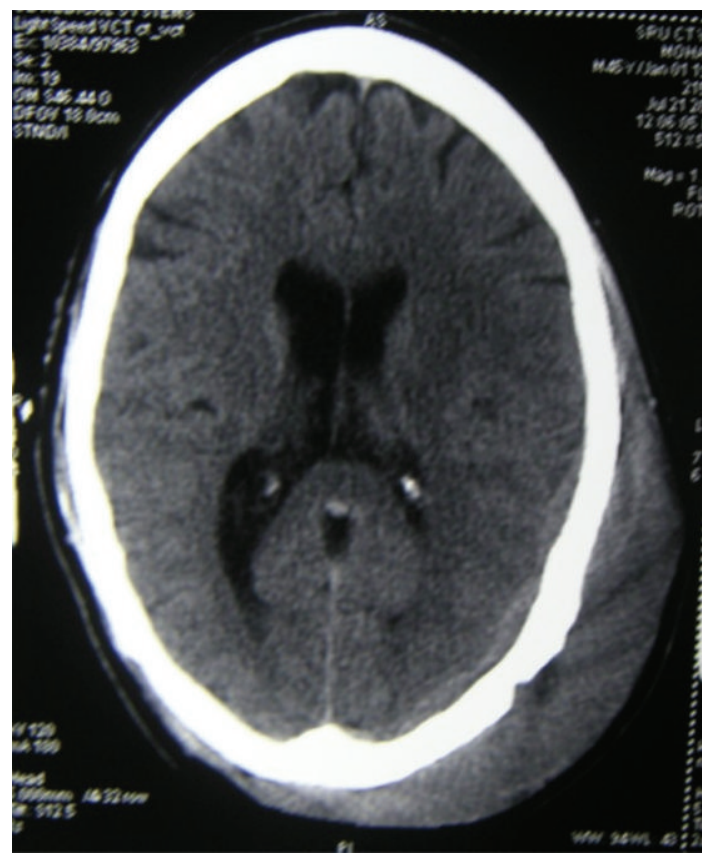

(a)

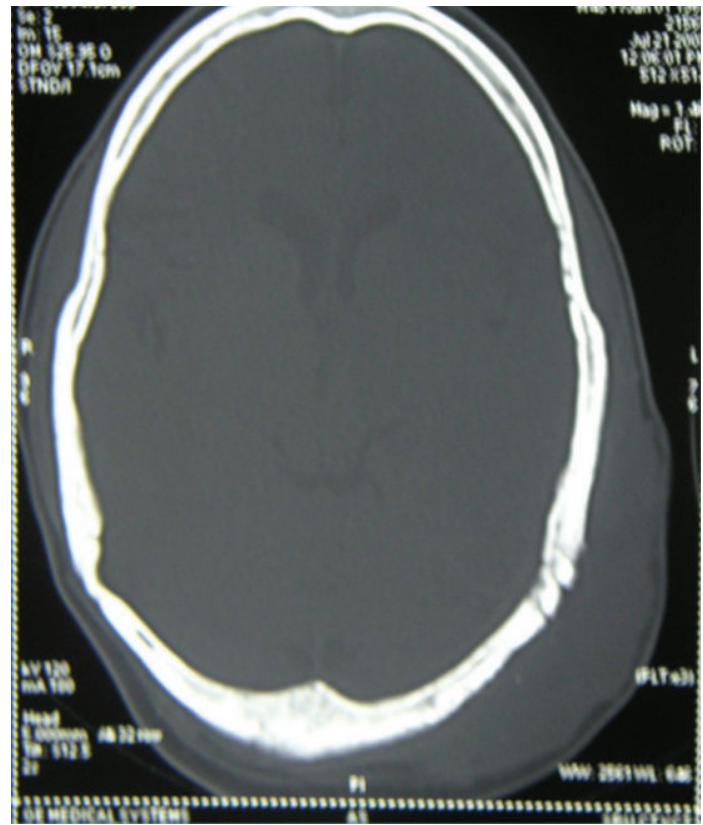

(b)

FIGURE 2: (a) CT scan axial section of the head showing scalp swelling in the left temporoparietal region after partial excision of the mass. (b) CT scan axial section showing scalp swelling after partial excision of the mass.

\section{Discussion}

Most primary cutaneous B-cell lymphomas (PCLs) have been reported involving the head and neck region and therefore PCL of the scalp needs to be differentiated from primary malignant Non-Hodgkin's lymphoma of cranial vault which is more frequently associated with intracranial (extradural) extension [2]. Other important clinicopathologic and radiological differential diagnoses include protruding tumorous angiolymphoid hyperplasia with eosinophilia (ALHE), Kimura's disease of the scalp, pseudolymphoma, cranial vault meningioma, and metastasis, and so forth
$[3,4]$. The main clinicoradiological differences between PCL of the scalp and primary NHL of the cranial vault include a shorter duration of symptomatology and early onset of focal neurological deficits, large soft-tissue mass, and extensive osteolytic lesions in primary NHL of the cranial vault. As seen in our case, the disease ran an indolent course over a period of one year with no intracranial/orbital invasion and subtle destruction of underlying bones by the diffusely infiltrating soft tissue mass [5]. Notwithstanding, primary malignant lymphoma originating from the skull may extend outside the cranium first and within the cranium subsequently and therefore at presentation more than half of 


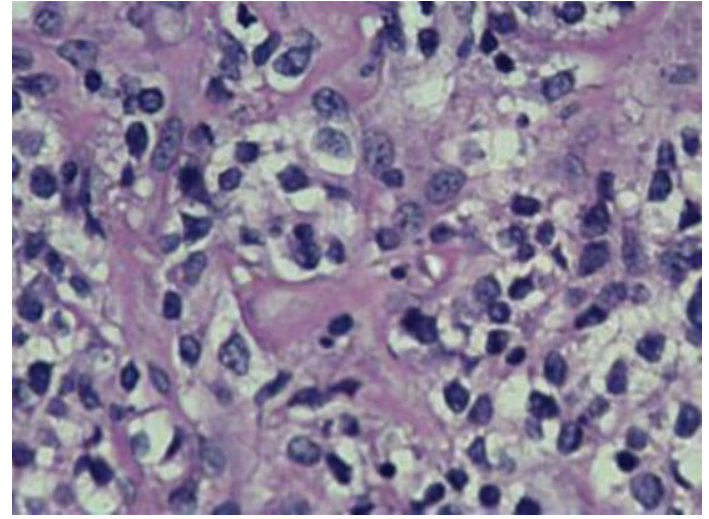

(a)

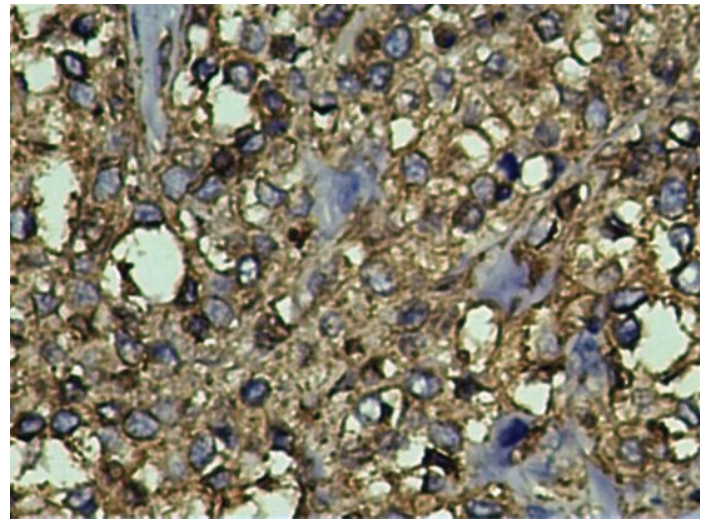

(b)

Figure 3: CD 20, CD 45 positivity.

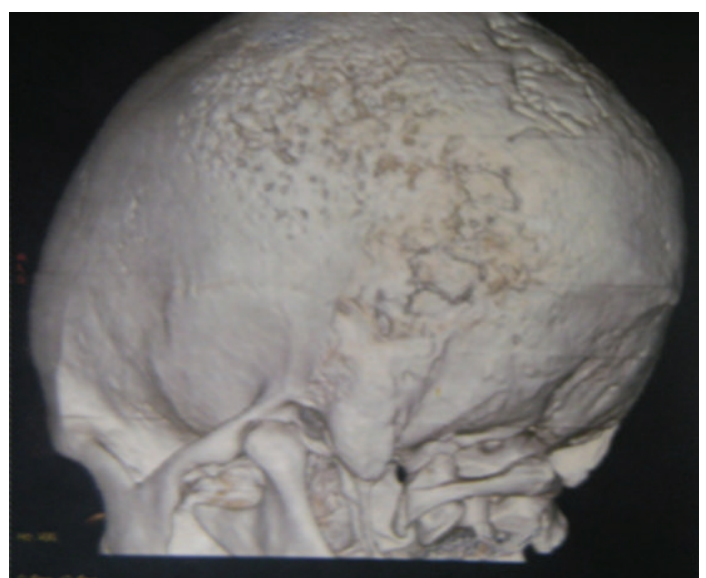

FIGURE 4: 3D reconstructed images of the skull.

the patients report a scalp mass rather than any neurological sign. Conversely, subcutaneous malignant lymphoma may involve the underlying skull and dura eventually $[6,7]$.

Most PCLs are hyperdense on unenhanced CT and show marked enhancement on postcontrast studies. Magnetic resonance imaging is important for evaluating local and regional spread to see involvement of bone marrow, leptomeninges, or dural venous sinuses [8].

Gallium scanning can rule out or confirm extracutaneous involvement and the presence or absence of activity in cases of gallium avid lymphomas is helpful in indicating the nature of residual soft tissue masses following chemotherapy/radiotherapy. Skin is the second most common site of extranodal lymphoma. Among them, 65\% are T-cell lymphomas (mycosis fungoides being the most common form of low-grade malignant peripheral cutaneous T-cell lymphoma), 25\% B-cell lymphomas, and about 10\% rare variants or nonclassifiable lymphomas. Only 15 to $25 \%$ of cutaneous lymphomas show extracutaneous manifestations at time of diagnosis. The prognosis is relatively good, since the average survival time from diagnosis is 12 to 14 years [9]. We are reporting this case because of its rare occurrence.
A diagnosis of primary lymphoma of the skull vault should always be considered in the differential diagnosis when such a lesion is encountered in middle aged and elderly patients.

\section{Conflict of Interests}

The authors declare that they have no conflict of interests.

\section{Disclosure}

I hereby transfer, assign, or otherwise convey all copyright ownership, including any and all rights incidental thereto, exclusively to the journal, in the event that such work is published by the journal.

\section{Authors' Contribution}

J. Martin contributed to concepts, design, definition of intellectual content, literature search, clinical studies, experimental studies, data acquisition, data analysis, statistical analysis, manuscript preparation, and manuscript editing, A. Ramesh to concepts, definition of intellectual content, clinical studies, experimental studies, data acquisition, data analysis, statistical analysis, manuscript preparation, and manuscript editing M. Kamaludeen to concepts, definition of clinical studies, experimental studies, data acquisition, data analysis, Udhaya to concepts, definition of intellectual content, clinical studies, experimental studies, data acquisition, data analysis, J. J. Martin to concepts, Experimental studies, data acquisition, and manuscript editing, K. Ganesh to clinical studies, experimental studies, and manuscript editing.

\section{References}

[1] A. B. Jamjoom, Z. A. Jamjoom, Naim-Ur-Rahman, and M. A. Cheema, "Primary midline cranial vault lymphoma simulating a parasagittal meningioma: the role of angiography in preoperative diagnosis," Neurosurgical Review, vol. 21, no. 2-3, pp. 202205, 1998. 
[2] R. Franco, A. Fernandez-Vazquez, J. L. Rodriguez-Peralto et al., "Cutaneous follicular B-cell lymphoma: description of a series of 18 cases," American Journal of Surgical Pathology, vol. 25, no. 7, pp. 875-883, 2001.

[3] A. Isla, F. Alvarez, M. Gutiérrez, C. Gamallo M et al., "Primary cranial vault lymphoma mimicking meningioma," Neuroradiology, vol. 38, no. 3, pp. 211-213, 1996.

[4] H. Kobayashi, T. Moriya, H. Tagami et al., "Protruding tumorous angiolymphoid hyperplasia with eosinophilia (ALHE) of the scalp accompanied by arterial occlusion," Journal of Dermatology, vol. 29, no. 1, pp. 38-42, 2002.

[5] M. Kantarci, T. Erdem, F. Alper, C. Gundogdu, A. Okur, and A. Aktas, "Imaging characteristics of diffuse primary cutaneous B-cell lymphoma of the cranial vault with orbital and brain invasion," American Journal of Neuroradiology, vol. 24, no. 7, pp. 1324-1326, 2003.

[6] S. Mongia, D. Shukla, B. I. Devi, and T. V. Reddy, "Primary cranial vault non-Hodgkin's lymphoma," Neurology India, vol. 51, no. 2, pp. 293-294, 2003.

[7] M. M. Thurnher, A. Rieger, C. Kleibl-Popov, and E. Schindler, "Malignant lymphoma of the cranial vault in an HIV-positive patient: imaging findings," European Radiology, vol. 11, no. 8, pp. 1506-1509, 2001.

[8] D. A. Duyndam, D. H. Biesma, and J. P. van Heesewijk, "Primary non-Hodgkin's lymphoma of the cranial vault; MRI features before and after treatment," Clinical Radiology, vol. 57, no. 10, pp. 948-950, 2002.

[9] G. Burg, R. Dummer, and H. Kerl, "Classification of cutaneous lymphomas," Dermatologic Clinics, vol. 12, no. 2, pp. 213-217, 1994. 


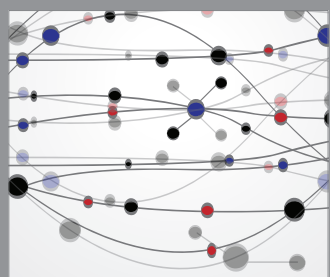

The Scientific World Journal
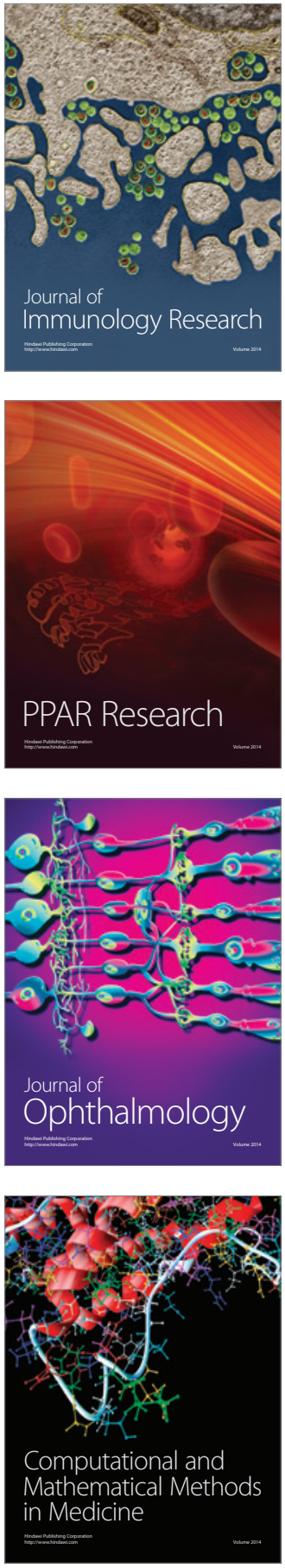

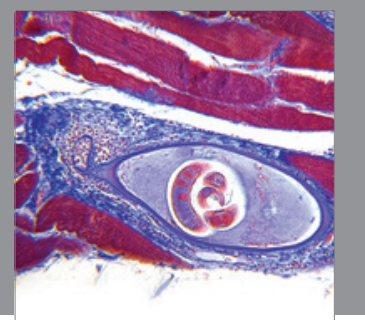

Gastroenterology

Research and Practice
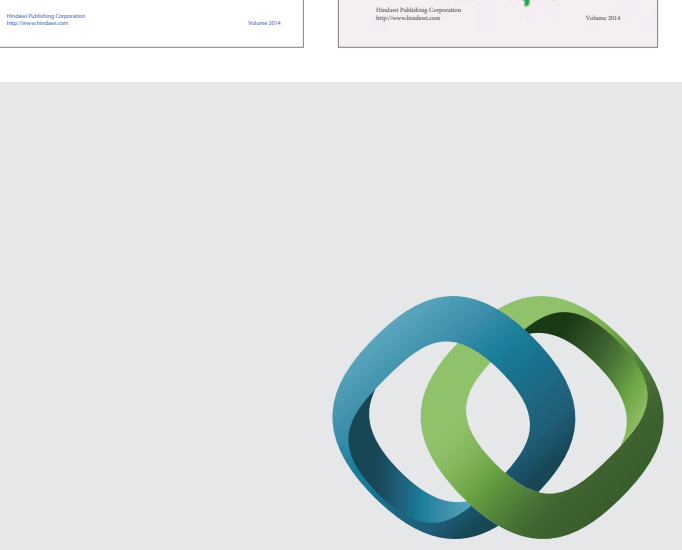

\section{Hindawi}

Submit your manuscripts at

http://www.hindawi.com
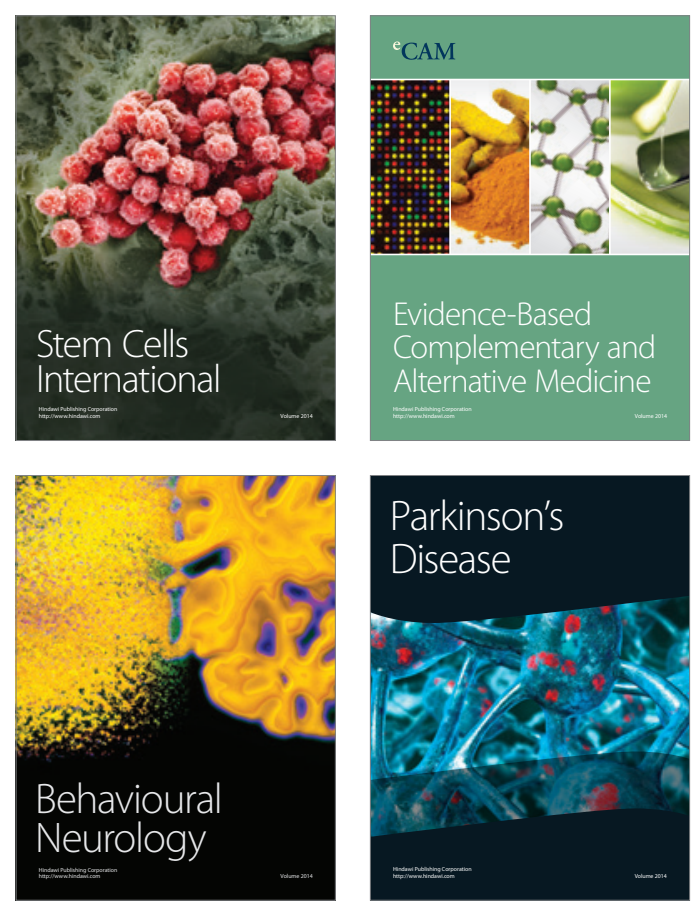

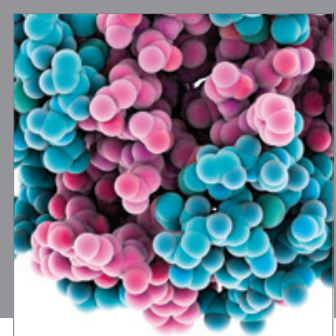

Journal of
Diabetes Research

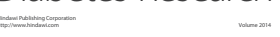

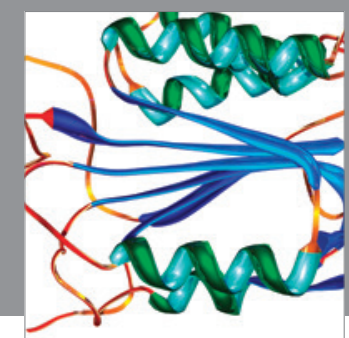

Disease Markers
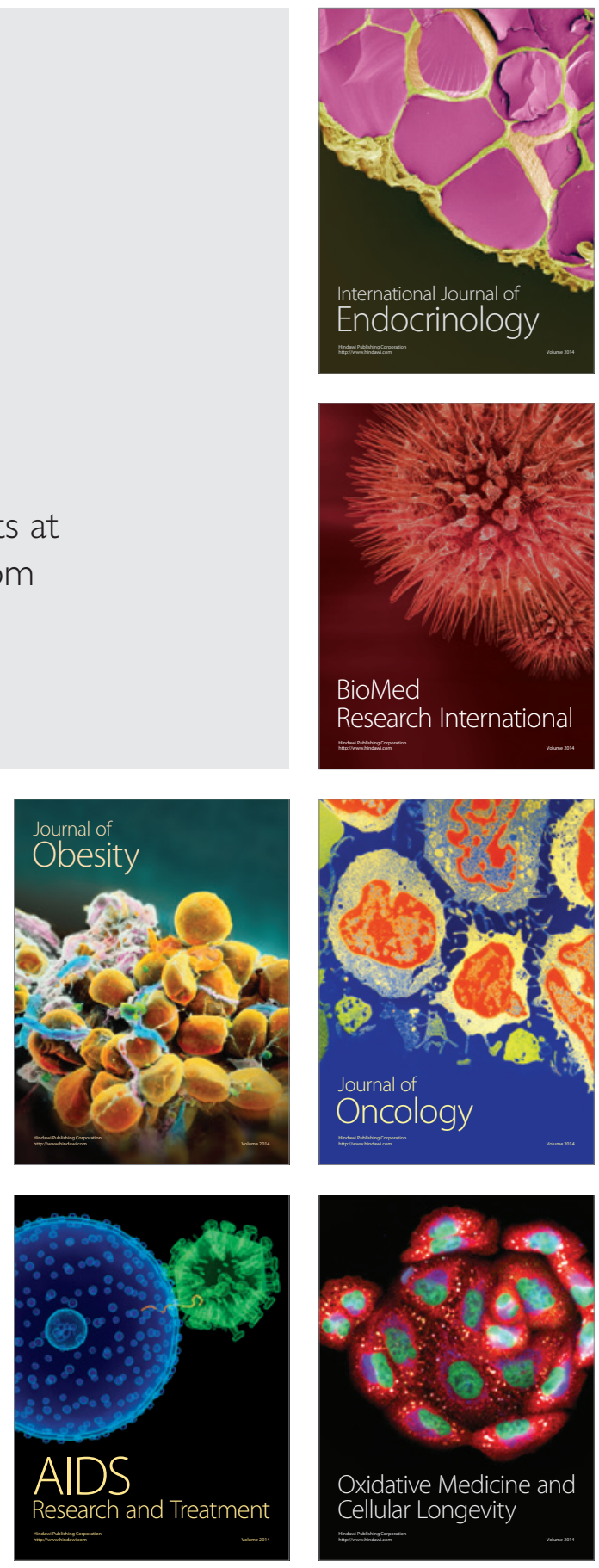